\title{
Nonlinearity of Diseases: Psychological Aspects
}

\author{
Dr. Amit Gosar
}

\begin{abstract}
The cause of both mental and physical diseases are generally attributed to few factors such as Germs and Genes in case of physical and nature and nurture in case of mental diseases. Acerbity of these factors to the disease is considered linear most of the time and according the therapies or treatment plans are generally decided. However, the fact is that the attributions or factors causing both mental and physical diseases and disorders are nonlinear. There is always a multidimensional and multidirectional relationship. And it is of at most importance to consider this fact while deciding on the treatment plan of any disease. In this article, efforts are made to understand different factors and their causal relationship for disease as a Meta study of several reported articles.
\end{abstract}

Index Terms - Nonlinearity, dynamic system, medicine system, psychological aspects of diseases, placebo effect.

\section{INTRODUCTION}

Quantitative scientific research generally follows a cause-effect relationship study, especially in medicinal discoveries. Cause and effect is one of the most commonly misunderstood concepts in science in an attempt to add legitimacy to research. This is mainly because to have an arithmetic expression to any scientific research, a linear mathematical expression is required. In case of developing medicines for any disease, the basic assumption made always is that the disease progresses in a linear manner. And there is always a cause which have the effect as a disease. This cause-effect relationship is again considered linear in modern medical scientific discoveries.

\section{NONLINEARITY OF HUMAN SYSTEM}

Human system is a dynamic system. Both naturally occurring and human made systems fall under both linear and dynamic nonlinear categories. Most of the natural as well as manmade systems are very complex and are nonlinear. They don't straight away fall in the liner cause-effect relationship. Since these linear considerations in case of dynamic systems doesn't yield satisfactory results, it's important to design a model which work beyond the boundaries of linear approximations.

The development of medicines for both physical and mental illnesses follows lot of simulation processes. These simulations are mainly based on drug receptor activity model. Since only two variables, drug and receptor are considered, the linear approach is always followed during the drug discovery stage. Even the drug testing at different phases (Phase I, II and III) is carried out by evaluating the effect in terms of blood concentration and the phenomenon is treated as a linear phenomenon.

Dr. Amit Gosar, Department of Masters in Business Administration, Sikkim Manipal University, Navi Mumbai, India
However, from the developmental cycle, it self we know that the growth of the human body is nonlinear and it follows two processes such as Cephalocaudal and Proximodistal. The dynamic human system, if not a perfect nonlinear system, it has a multi linearity aspects due to its dynamic nature. Systems such as Endocrine system, emotions, thoughts etc are multidimensional and multidirectional systems and cannot be explained with linear relationship.

In addition to emotions and thoughts, the very important and critical phenomenon to be considered here is the consciousness. Deepak Chopra in his research on quantum physics have elaborated his work on the consciousness. The human body and behavior are considered as an expression of mind. As described by Sigmund Freud, the mind has multiple components as conscious, preconscious, subconscious, unconscious and nonconscious components and the ids residing in the subconscious mind of an individual plays a great role in the way his behavior is tuned.

Our perceived reality is classical, that is it consists of material objects and their fields. On the other hand, reality at the quantum level is different in as much as it is nonlocal, which implies that objects are super positions of other entities and, therefore, their underlying structure is wave-like, that is it is smeared out. This discrepancy shows up in the framework of quantum theory itself because the wave function unfolds in a deterministic way excepting when it is observed which act causes it to become localized.

As Carl Roger elaborates on Real self, Ideal self and Perceived self and the congruence between them leads to Homeostasis. This Homeostasis has a great influence on acquisition of mental and physical illnesses. The body, which is in perfect homeostasis, will have great immunity towards both mental and physical illnesses. This clearly indicates that the consciousness of human mind, which is so vast and nonlinear has great impact on human system. And thus human system cannot be studied with simple linear algorithms.

\section{NONLINEARITY OF ECOLOGICAL EFFECTS}

"We argue that the analytic framework used by researchers who have discussed the ecological fallacy"-13 is inappropriate in the case of infectious diseases because that framework implies dynamic linearity of disease development in a population. Dynamic linearity occurs when the rate of disease development in one group is independent of how many individuals there are in other groups. When the assumption of dynamic linearity does not hold, statistics estimated using models that assume dynamic linearity do not accurately reflect the effect of exposures at either the individual or the population level. More specifically, when nonlinear population processes generate dependence of outcomes between individuals, neither regression coefficients from ecological studies nor risk differences from individual studies reflect how much change in disease levels can be 
expected from a given change in exposure levels" - James S. Koopman et al (1994).
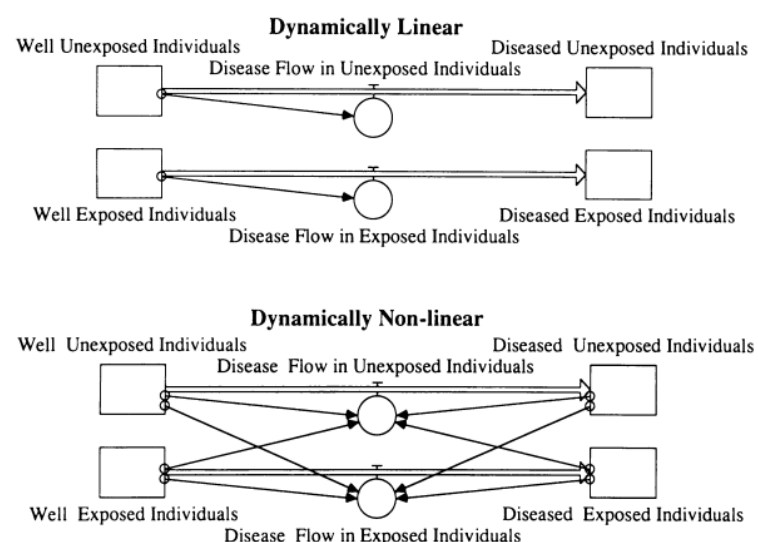

Disease Flow in Exposed Individuals

Figure 1: An Illustration of linear and nonlinear dynamic systems : source : James S. Koopman, MD, MPH, and Ira M. Longini, Jr, PhD; The Ecological Effects of Individual Exposures and Nonlinear Disease Dynamics in Populations; American Journal of Public Health; May 1994, Vol. 84, No. 5, 836 - 842.

This clearly indicates, that there is a huge impact of ecological components on the human system. This effect again is a multidimensional and multidirectional leading to make the human system further more complex in terms of evaluation of cause-effect relationship in linear mathematical function.

\section{MURPHY'S LAW}

Murphy's Law is one of such laws which stands true always and is a doctrine. It states that "things will go wrong in any given situation, if you give them a chance," or more commonly, "whatever can go wrong, will go wrong."

The sole purpose of quoting this law here is to support the understanding of fallacy of linear consideration to a dynamic human and ecological system. The major failure of most of the modern medicines in exerting desire effects to the expected extent and to have zero side effects can be accounted by this law. If, the linear relationship, between disease and the medicine has been true, there haven't been any side effects of drugs. There are many reported incidences, where the diseases have been completely cured by administering placebo instead of the drug. This placebo effect can never be explained by linear considerations.

Factors responsible for acquiring a disease:

Deepak Chopra in his article "The Mystery of illness" delineated various causes for acquiring a disease. His illustration of Germ theory Vs. Gene theory can be considered a part of Nature Vs. Nurture debate. It is a common assumption by most of the population that either Germs or Genes are the cause for any diseases. Both Germ theory and Gene theory have gone long way in explaining the causal relationship for the diseases. However, there is still lies a secret that why some people get ill, while others do not, even though the external environments for them is common. For example, many researches have shown that if cold virus is directly placed into an individual's nose, the chance of acquiring a cold is just 1 in 8; moreover, exposer to chill, damp, or a draft doesn't increase these odds.

In fact, each of us are inhaling sufficient germs every day to contract various diseases, which we actually never contract. There is a sort of coping mechanism always working against it. This coping mechanism is more effective when the individual is at homeostasis.

The multiple conditions, both physical and mental, when come together provides sufficient stimulus condition for an individual to acquire mental of physical illnesses. These conditions are well illustrated by Deepak Chopra in his article as follows.

Unsanitary conditions: massive exposure to germs remains a major factor.

Being poor: poverty degrades life on all fronts, including health.

High stress: physical and psychological stress damage the immune system.

Depression and anxiety: untreated psychological disorders weaken resistance to a wide range of diseases, perhaps even cancer

Lack of coping mechanisms: stress by itself is a negative factor, but the inability to bounce back from it is more important.

Lack of control, victimization: all stresses become much worse if you feel that you have no control over your own life. Inertia, sedentary lifestyle: if you are inactive and have no outside interests, your chance of getting sick rises sharply

Feeling alone and unloved: emotional deprivation is as unhealthy as deprivation of good food.

Sudden loss: the sudden loss of a job or spouse, a reversal in finances, or finding yourself in the midst of a war or natural disaster all constitute a state of loss and lead to higher risk of getting sick.

Growing old: once considered a major cause of illness, aging is now known not to be a direct cause. Being healthy into your eighties should be your expectation, but if you neglect yourself in old age, the body becomes vastly more susceptible to disease.

\section{CONCLUSION}

The human system of mind, body, emotions and consciousness is a dynamic nonlinear system. This system is a multidimensional and multidirectional system and cannot be simulated by considering simple and linear algorithmic systems. The psychological aspects of conscious and subconscious mind plays a very critical role in the behavior of human and human body. The quantum physics also explains it in an effective way as the human body being an expression of the mind. Thus the perceived reality in the object world is a product of quantum consciousness. The disease is a state of non-congruency between the Real, Ideal and Perceived selves. The complete homeostasis occurs only when these selves are in congruence with each other. Hence, the modern medical science will have to work beyond the linear consideration of cause-effect method for drug interaction in treating any mental of physical disorder.

\section{REFERENCES}

[1] James S. Koopman, MD, MPH, and Ira M. Longini, Jr, PhD; The Ecological Effects of Individual Exposures and Nonlinear Disease 
Dynamics in Populations; American Journal of Public Health; May 1994, Vol. 84, No. 5, 836 - 842.

[2] Amit Gosar*; "Direction of life". GJRA, 7(11): 416 - 418, 2018

[3] Deepak Chopra; The mystery of illness; www.beliefnet.com

[4] Subhash Kak , Deepak Chopra , and Menas Kafatos; Perceived Reality, Quantum Mechanics, and Consciousness; Cosmology, 2014, Vol. 18. 231-245

[5] Robert A. J. Matthews; The Science of Murphy's Law; Scientific American, April 1997, page 88- 91.

[6] Tumbling Toast, Murphy's Law and the Fundamental Constants; R.A.J. Matthews in European Journal of Physics, Vol. 16, pages 172-176; June 1995.

[7] John P. Higginsa; Nonlinear Systems in Medicine; yale journal of biology and medicine, 75 (2002), 247-260.

[8] Hans J. (Jochen) Scholl; Introduction to Modeling Nonlinear Natural and Human Systems Minitrack; Proceedings of the 35th Hawai International Conference on System Sciences - 2002.

[9] S. E. Phelan, "A note on the correspondence between complexity and systems theory," Systemic Practice and Action Research, vol. 12, 237-246, 1999.

[10] L. Brizhik and A. Foletti; nonlinear quantum phenomena and biophysical aspects of Complexity related to health and disease; journal of biological regulators \& homeostatic agents, 28 (3), 367 - 376, 2014.

[11] Pollack GH. Water, energy and life: Fresh views from the water's edge. Int J Des Nat Ecodyn 2010; 5:27-9.

[12] Freud, S. (1915). The unconscious. SE, 14: 159-204.

[13] Freud, S. (1920). Beyond the pleasure principle. SE, 18: 1-64

[14] Freud, S. (1923). The ego and the id. SE, 19: 1-66.

[15] Freud, S. (1925). Negation. Standard edition, 19, 235-239.

[16] Freud, S. (1961). The resistances to psycho-analysis. In The Standard Edition of the Complete Psychological Works of Sigmund Freud, Volume XIX (1923-1925): The Ego and the Id and other works (pp. 211-224).

[17] Rogers, C. (1951). Client-centered therapy: Its current practice, implications and theory. London: Constable.

[18] Rogers, C. (1959). A theory of therapy, personality and interpersonal relationships as developed in the client-centered framework. In (ed.) S. Koch, Psychology: A study of a science. Vol. 3: Formulations of the person and the social context. New York: McGraw Hill.

[19] Rogers, C. R. (1961). On Becoming a person: A psychotherapists view of psychotherapy. Houghton Mifflin.

[20] Rogers, C. R., Stevens, B., Gendlin, E. T., Shlien, J. M., \& Van Dusen, W. (1967). Person to person: The problem of being human: A new trend in psychology. Lafayette, CA: Real People Press.

First Author : Dr. Amit Gosar, Ph.D. (Chemistry), MBA is an Analytical Research Head at Indoco Remedies Ltd. He is also a research guide at Sikkim Manipal University. He has over 20 years of experience in the field of Research. He is a Psychotherapist, Clinical Hypnotherapist, NLP master practitioner and a life coach. He has over 10 years in the field of therapy. He has over 35 publications in the fields of Chemistry, Psychology and Management. He has a professional member ship of IAAP (International association of applied psychology), CTAA (Complementary Therapists Accredited Association) and Leaders Excellence at Harvard Square. 